1 Universidade Federal da Bahia (UFBA), Instituto de Saúde Coletiva (ISC) Salvador (BA), Brasil. catharinamatos@gmail.com

2 Universidade Federal da Bahia (UFBA), Instituto de Saúde Coletiva (ISC) Salvador (BA), Brasil. mayarafreitas.ufba@gmail. com

3 Universidade Federal da Bahia (UFBA), Instituto de Saúde Coletiva (ISC) Salvador (BA), Brasil. carment@ufba.br

4 Universidade Federal da Bahia (UFBA), Instituto de Saúde Coletiva (ISC) Salvador (BA), Brasil. jairnil@ufba.br

\section{Análise do posicionamento das Entidades Médicas - 2015-2016}

Positioning analysis of Medical Entities - 2015-2016

Catharina Matos Soares', Mayara Santana de Freitas², Carmen Fontes Teixeiraㄹ, Jairnilson Silva Paim4

RESUMO O objetivo deste artigo é o de relatar pesquisa que analisou o posicionamento das Entidades Médicas (EM) sobre política e sistema de saúde no Brasil em 2015 e 2016. Realizouse o acompanhamento, processamento e classificação das notícias publicadas em três sites oficiais de EM, totalizando 648 publicações. A maior parte das publicações se encontrava no Conselho Federal de Medicina (CFM) e na Federação Brasileira dos Médicos (Fenam), sendo 44\% em cada site. O Programa Mais Médicos e o Movimento Médico foram os temas mais frequentes nas publicações, os quais manifestaram oposição das entidades às políticas estabelecidas pelo governo federal antes do impeachment. Os resultados indicam que as EM defendem interesses corporativos, distanciando-se dos princípios e diretrizes da Reforma Sanitária Brasileira.

PALAVRAS-ChAVE Política de saúde. Medicina. Reforma dos serviços de saúde.

ABSTRACT The objective of this paper is to report a research that analyzed the Medical Entities (EM) understanding on health policy and the health system in Brazil in 2015 and 2016. Monitoring, processing, and classification of news released in three official MS sites were carried out, totaling 648 subjects. Most of the publications were found in Conselho Federal de Medicina (CFM) and Federação Brasileira dos Médicos (Fenam), being 44\% in each site. 'More Medical Program' and 'Medical Movement' were the most frequent themes in the publications, which expressed opposition of the entities to the policies established by the Federal Government before the impeachment. The results indicate that EM advocate corporate interests, deviating themselves from the principles and guidelines inherent to the Brazilian Health Reform.

KEYWORDS Health policy. Medicine. Health care reform. 


\section{Introdução}

A Reforma Sanitária Brasileira (RSB) vem sendo estudada como processo desencadeado em meados dos anos 1970, que envolveu múltiplos atores e implicou a produção de um conjunto heterogêneo de fatos políticos em diversos espaços. Nascido no seio da sociedade civil, a partir da articulação de um conjunto de docentes e pesquisadores, ao lado do segmento estudantil e de grupos organizados da população, o projeto da RSB caracterizou-se pela mobilização de entidades profissionais e populares em defesa da democracia, configurando-se em amplo movimento pelo reconhecimento do direito à saúde e pela construção de um sistema universal de saúde (ESCOREL, 1998; PAIM, 2008; TEIXEIRA ET AL. 2014).

Em sua origem, a RSB contou, entre seus protagonistas, com a participação de Entidades Médicas (EM) articuladas em torno do movimento que ficou conhecido como Renovação Médica (CAMPOS, 1988). Essa iniciativa resultou na mobilização de muitos profissionais da categoria em torno das eleições para a direção de associações, sindicatos e conselhos, aglutinando segmentos insatisfeitos com a política de saúde vigente, as condições de trabalho e remuneração dos profissionais e a condução das EM durante o regime militar (ESCOREL, 1998).

De fato, as transformações ocorridas no mercado de trabalho médico em razão do processo de expansão das empresas médicas implicou o assalariamento de grande parte do contingente de profissionais, formados, inclusive, pelas novas escolas médicas criadas após a Reforma Universitária de 1968, a maioria delas privadas (DONNANGELO, 1975). Esse processo contribuiu para o questionamento da ideologia liberal que conforma a profissão médica e estimulou a criação e fortalecimento dos sindicatos da categoria (CAMPOS, 1988; DONNANGELO, 1975), facilitando, portanto, a adesão de jovens lideranças ao movimento pela RSB, culminando com a realização da VIII Conferência Nacional de
Saúde, cujo relatório sistematiza a proposta de mudança de política e a organização dos serviços de saúde.

Estudos mais recentes sobre a RSB (BAHIA, 2010; COSTA ET AL., 2013; MACHADO ET AL., 2012; OCKÉ-REIS, 2012; TEIXEIRA; PAIM, 2005;) indicam continuidades e mudanças, centrando-se nos processos desenvolvidos no âmbito do Ministério da Saúde (MS) sem aprofundar a análise da participação de outros atores no processo da RSB.

Objetivando preencher essa lacuna, elaborou-se projeto de investigação que contempla o mapeamento de diversos atores políticos e a análise do seu posicionamento diante da RSB e do Sistema Único de Saúde (SUS) no período 2013-2016, na tentativa de identificar suas possíveis relações com projetos políticos em disputa na sociedade brasileira. Este estudo faz parte do eixo da pesquisa 'Análise do Processo da Reforma Sanitária Brasileira no período de 2007 a 2016', disponível em www.analisepoliticaemsaude.org, e trata, especificamente, do posicionamento das EM nos Governos Dilma Rousseff e Michel Temer, particularmente nos anos 2015 e 2016, período marcado pela implantação do Programa Mais Médicos (PMM).

Sobre a atuação política das EM, o estudo de Gomes (2016) analisou a atual configuração da categoria médica no Brasil e concluiu que tanto as EM como os militantes que atuaram por fora delas, se articularam no período de implantação do PMM, as primeiras, contrárias à implantação do Programa, e os militantes, em boa parte, em sua defesa.

$\mathrm{Na}$ ausência de mais pesquisas sobre o tema, indagou-se acerca do posicionamento das EM com relação à política e ao sistema de saúde na conjuntura atual e os fatos políticos produzidos por esses atores, de forma a compreender e discutir as implicações desse posicionamento para o processo de consolidação do SUS e da RSB.

Neste estudo, tratou-se, ademais, de examinar o posicionamento das EM quanto a sua aproximação e distanciamento em relação ao projeto da RSB. Assim, o estudo teve como 
objetivo identificar, sistematizar e analisar o posicionamento das EM, cotejando-o com as diretrizes emanadas do governo federal em relação ao SUS no biênio 2015-2016.

\section{Metodologia}

Foram analisados os fatos políticos produzidos por três EM de caráter nacional no período 2015 e 2016, compreendendo os Governos de Dilma Rousseff e Michel Temer. Acompanharam-se diariamente, de $1^{\circ}$ de janeiro de 2015 a 31 de dezembro de 2016, as notícias que trataram das questões relativas às políticas e o sistema de saúde brasileiro em três sites de EM, quais sejam: Conselho Federal de Medicina
(CFM), disponível em http://portal.cfm.org. br/, Associação Médica Brasileira (AMB), disponível em http://amb.org.br/, e Federação Brasileira dos Médicos (Fenam), disponível em http://www.fenam.org.br/.

As notícias foram coletadas na integra e na sequência, lidas e resumidas. $O$ resumo foi processado em planilha Excel contendo os campos data, tema e notícia; acontecimento ou fato, no resumo da notícia; fonte; e link para a notícia. Excluíram-se notícias de eventos, de saúde geral sem correlação com as políticas ou com o sistema de saúde brasileiro, e notícias locais. Na matriz Excel, as notícias foram classificadas em dez categorias de análise (tabela 1), por tema abordado.

Tabela 1. Número de publicações no período 2015-2016, por categoria de análise

\begin{tabular}{lrr}
\hline Categorias & No de Matérias & $\mathbf{( \% )}$ \\
\hline Programa Mais Médicos & 141 & $21,8 \%$ \\
Movimento Médico & 96 & $14,8 \%$ \\
Atenção à saúde & 79 & $12,2 \%$ \\
Outros & 77 & $11,9 \%$ \\
Conjuntura nacional & 68 & $10,5 \%$ \\
Gestão do trabalho em saúde & 57 & $8,8 \%$ \\
Financiamento do SUS & 44 & $6,8 \%$ \\
Vigilância em saúde & 43 & $6,6 \%$ \\
Saúde suplementar & 30 & $4,6 \%$ \\
Políticas de saúde específicas & 13 & $2 \%$ \\
Total & 648 & $100 \%$ \\
\hline
\end{tabular}

Fonte: AMB (2016); CFM (2016); Fenam (2016).

A análise do conteúdo das notícias foi feita tomando como referencial o entendimento das EM como organizações que representam os interesses dessa categoria profissional, e que, como tal, participam do processo político em saúde, interferindo, direta ou indiretamente, na tomada de decisões governamentais com relação a diversos aspectos do processo de gestão do sistema de saúde, especialmente às questões relacionadas à gestão do trabalho, isto é, à geração de empregos, à distribuição territorial da força de trabalho em saúde, à política salarial e a outros aspectos relacionados, como é o caso da política de formação profissional em nível da graduação e pós-graduação, que define o 
volume da oferta e perfil profissional lançado ao mercado de trabalho.

Todos esses aspectos fazem parte da agenda política das EM e constituem objeto de debate, posicionamento e negociação com as instituições do Estado responsáveis pelas políticas econômicas e sociais, particularmente nas áreas de saúde e educação. Seus posicionamentos podem ser de apoio ou rejeição das políticas governamentais, o que, em última análise, contribui para a legitimação e fortalecimento ou invalidação das propostas apresentadas. Nesse particular, a relação entre EM e instituições do Estado geram fatos políticos em saúde, ou seja, aqueles produzidos no âmbito do Estado, por seus setores e organizações, a partir da interação de distintos agentes sociais com objetivos e interesses convergentes ou divergentes e com distintas capacidades acumuladas (ALENCAR, 2016).

\section{Resultados}

As publicações analisadas apresentaram igual número para o CFM e a Fenam, ambas com 285 publicações, representando $44 \%$ das notícias cada, e a AMB dispôs de 78 notícias, totalizando $12 \%$ da produção. Dentre elas, o 'Programa Mais Médicos' relacionou 141 matérias, englobando 'Formação Médica' e 'Programa Mais Especialidades'. As matérias relacionadas ao 'Movimento Médico' ocuparam a segunda posição, agrupando 96 publicações. Já a categoria 'Outros', reuniu o quarto maior grupo de notícias, computando 77 publicações de temas variados, como diretrizes para o parto, bioética, judicialização da saúde, regulação, o mercado de órtese e prótese, dentre outros (tabela 2).

Tabela 2. Número de publicações no período 2015-2016, por entidade

\begin{tabular}{lrr}
\hline Entidades & № de Matérias & (\%) \\
\hline AMB & 78 & $12 \%$ \\
CFM & 285 & $44 \%$ \\
Fenam & 285 & $44 \%$ \\
Total & 648 & $100 \%$ \\
\hline
\end{tabular}

Fonte: AMB (2016); CFM (2016); Fenam (2016).

\section{A polêmica em torno do PMM}

Por ocasião da comemoração do segundo aniversário do PMM, as EM, por meio da Fenam, afirmaram que o governo estava sendo oportunista pela tentativa de desviar a atenção do povo brasileiro da grave crise política enfrentada pela então Presidente da República, Dilma Rousseff. No artigo 'Menos médicos e menos saúde', o presidente do CFM, menciona que os projetos governamentais na área da saúde são elaborados com apriorística atenção ao 'tempo político', imprescindível ao êxito eleitoral. Segundo ele, a população carente, a que mais precisa do SUS, seria a mais prejudicada.

[...] Não há políticas de Estado, apenas fragmentadas políticas de governo, sem continuidade nem reverência a princípios fundamentais, que não possuem financiamento compatível nem competência administrativa, é desprovido de controle, de avaliação e de planejamento adequados, submetido ao descaso. (CFM, 2016, N. P.). 
[...] Infelizmente, o programa foi usado política e eleitoralmente. Precisamos é sair do discurso enganoso de que isso vai melhorar a saúde no Brasil. [...] Defendemos o SUS como foi concebido, que é bastante diferente da propaganda e do que aflige e faz sofrer nosso povo. (AMB, 2016, N. P.).

A insatisfação das EM com base no relatório do Tribunal de Contas da União (TCU) e do Ministério Público do Trabalho que, revelou diversas falhas nos contratos dos médicos cubanos como também na atuação dos profissionais no PMM, reacendeu as tensões entre as EM e o MS.

No congresso, em apoio à visão liberal das EM, o senador Ronaldo Caiado (Democratas - DEM-GO) e outros senadores de partidos ditos democráticos, afirmaram que o programa é um disfarce para apoiar a ditadura cubana e mandar dinheiro àquele País; e que o termo de cooperação representa um "acordo bilateral realizado entre o governo brasileiro e o de Cuba com o objetivo de transferir dinheiro à ditadura cubana" (FENAM, 2016, N. P.). Houve crítica também à Medida Provisória $n^{0} 723 / 16$, que prorrogou a permanência dos intercambistas cubanos no PMM. Segundo as EM, o governo estava ignorando o grande contingente de médicos formados no Brasil, com diplomas válidos.

[...] O Brasil, que passa por um período de grave recessão, continuará a enviar bilhões de reais para o exterior por meio da Organização Pan-americana de Saúde (Opas), em vez de assegurar que esses recursos fiquem em sua integralidade dentro de nossas fronteiras. 'Ao fazer isso, o Governo daria emprego para nossos profissionais que, por sua vez, com seus rendimentos, ajudariam a aquecer a economia de Estados e Municípios'. (CFM, 2016, N. P.).

Já no governo Temer, a Fenam noticiou declarações do ministro da saúde Ricardo Barros, que afirmava que o PMM era provisório. Isso, porque, segundo ele, na organização dos serviços de saúde, cabe aos municípios e não ao governo federal a responsabilidade de contratar os profissionais, apoiando, de certa forma, o posicionamento das EM.

A formação médica, uma das diretrizes do PMM, foi objeto de debate desde a graduação até a residência médica e, especialmente, dos impactos do PMM sobre ambas. O CFM criticou a distribuição de vagas dos cursos de medicina oferecidas pelo Sistema de Seleção Unificada (Sisu) por todo o Brasil e a interiorização da medicina no País, já que essa expansão para o interior fica a cargo de instituições privadas. Para a entidade, o Sisu não confirma a interiorização proposta, dado que foram abertos poucos novos cursos públicos. Ademais, o Ministério da Educação (MEC) avalizou a aprovação de novas vagas da graduação em 36 cidades brasileiras sem cumprimento dos requisitos básicos de infraestrutura exigidos em edital. Dentre as cidades pré-selecionadas, só nove reuniam condições para abrigar o curso.

[...] estão abrindo unidades em locais que claramente não têm condições de receber cursos de Medicina, por não haver a infraestrutura adequada. [...] $\mathrm{O}$ que fixa esses profissionais nessas áreas são as condições de trabalho, em primeiro lugar, acompanhadas pelas condições sociais e a remuneração. A residência médica também é importante. (CFM, 2016, N. P.).

Com efeito, o CFM ingressou na Justiça Federal, em Brasília, com duas ações de obrigação de fazer, com pedido de tutela antecipada contra o MEC e instituições de ensino superior, que, mesmo sem condições técnicas e legais, passariam a ofertar cursos de medicina. Nesse particular, o Tribunal de Contas da União (TCU) acabou por acatar a ação e suspendeu, em novembro de 2015, a abertura de 2460 vagas de medicina em universidades particulares no País devido a possíveis irregularidades na licitação.

Com o objetivo de mapear a qualidade no ensino médico no País, o CFM realizou 
estudo denominado 'Radiografia das Escolas Médicas do Brasil', revelando que a quantidade de cursos particulares de medicina no Brasil, a partir do PMM, mais do que dobrou em relação ao ritmo de abertura de estabelecimentos públicos, contradizendo o posicionamento do governo federal que, à época, afirmara que estava fechando um 'balcão de negócios'.

[...] Infelizmente, o que temos visto são faculdades desqualificadas, com corpo docente despreparado; algumas não possuem sequer hospital-escola. Isso resultará em médicos malformados, o que compromete a qualidade do atendimento. [...] Não se trata de reserva de mercado. O país precisa de mais profissionais sim, mas nossa preocupação é com a qualidade da formação. [...] Um estudante que não é avaliado, minimamente coloca em risco a vida dos pacientes [...]. As escolas são autorizadas a funcionar com pendências que não são resolvidas. Os cursos são criados mesmo sem hospital conveniado, insumos e materiais de laboratório. O MEC tem que visitar essas escolas, mas, muitas vezes, os primeiros cursos terminam, o aluno recebe o diploma e a avaliação não é feita. Há uma liberalidade indevida. (CFM, 2016, N. P.).

A criação de faculdades de medicina para fixar médicos em cidades pequenas é vista então como um erro do governo em análise

[...] É mais um exemplo de uma política equivocada para a saúde no Brasil. Esse governo acredita que pode resolver problemas estruturais com uma canetada, sem discutir com quem conhece formação médica. (AMB, 2016, N. P.).

Também, a reformulação das diretrizes curriculares nacionais para a graduação em medicina foi objeto de crítica pelas EM. Criticaram a exclusão de docentes, discentes, médicos e sociedade do debate e construção da proposta. As novas Diretrizes, instituídas no bojo da formulação da Lei do
'Mais Médicos', apresentam, para as entidades, como alguns dos pontos críticos, a determinação de que $30 \%$ da carga horária do internato deverá ser cumprida no sistema público e que os estudantes sejam avaliados pelo governo a cada dois anos, em avaliação seriada. Ainda, a avaliação seria obrigatória e o resultado, contado como parte do processo de classificação para os exames dos programas de residência médica. O Conselho disse estar preocupado com os aspectos que serão reforçados neste formato de avaliação, visto que,

na elaboração das diretrizes curriculares de 2001, tivemos autonomia, discutimos por três ou quatro anos como deveria ser o modelo da educação médica. (CFM, 2016, N. P.).

No que tange à avaliação seriada dos estudantes, o CFM proibiu os Conselhos Regionais de Medicina (CRMs) de implantar exames para avaliar os egressos dos cursos, em caráter obrigatório ou coercitivo, como exigência para registro ou inscrição do médico.

[...] A Resolução 2.130/2015, do Conselho Federal de Medicina (CFM), que já está em vigor, torna sem efeito os atos normativos contrários. De acordo com a Lei 3.268/57, que trata do funcionamento dos Conselhos de Medicina, os atos normativos editados pelo CFM devem ser seguidos pelos CRMs, inclusive como parâmetro para formulação e edição de suas próprias decisões. (CFM, 2016, N. P.).

Como consequência do descontentamento gerado pelas mudanças produzidas pelo PMM na formação médica, as EM iniciaram um projeto piloto de acreditação de cursos de medicina por meio do Sistema de Acreditação das Escolas Médicas (Saeme), para fins de contribuição ao aperfeiçoamento do ensino médico no Brasil. Tratase de um instrumento que promove maior participação da comunidade acadêmica e 
da sociedade para o desenvolvimento de visão crítica sobre a qualidade dos cursos de medicina no Brasil.

O Exame Revalida, necessário para atuação de médicos estrangeiros no Brasil, foi também objeto de posicionamento das EM, que se articularam com a Comissão de Relações Exteriores e Defesa Nacional (CRE) do senado para aprovação do projeto que obriga os médicos formados em universidades estrangeiras a passar por esse exame. Todavia, as EM continuaram criticando, durante todo período de estudo, a decisão do governo em permitir que médicos formados em outros países atuem no Brasil antes de aprovação no Revalida por meio do PMM.

Em 2016, foi instituída a portaria 168 para regulamentação da Avaliação Nacional Seriada dos Estudantes de Medicina (Anasem), que prevê exames periódicos durante a graduação e ao final do curso. Para as EM, o exame representa um importante teste de progresso, embora a portaria 168 não se apresentasse de forma adequada. O embate entre EM e governo federal sobre o tema provocou o recuo do governo, que se comprometeu com a publicação de nova portaria.

[...] é uma portaria muito polêmica, não esclarece como será no caso de o aluno ser reprovado, e como poderá fazer novamente a prova, dizem que é um teste de progresso, mas isto não é um teste de progresso, continuam permitindo a proliferação indiscriminada de faculdades, e quando são de má qualidade punem o aluno no final. (FENAM, 2016, N. P.).

Ainda no escopo do tema formação médica, em abril de 2015, o então ministro da saúde, Arthur Chioro, anunciou que preparava uma nova etapa do PMM, o Programa Mais Especialidades (PME), apresentando em 4 de agosto de 2015, por meio do Decreto $\mathrm{n}^{0} 8497$, que regulamentou o Cadastro Nacional de Especialistas. Para as entidades, as mudanças nas regras para formação de especialistas no Brasil eram uma interferência autoritária por parte do Poder Executivo na capacitação de médicos especialistas no País. Reclamaram, também, da ausência de diálogo entre o governo e os representantes das EM, das universidades e dos residentes. A partir daí, uma série de publicações foi veiculada nos sites das entidades médicas, posicionando-se e mobilizando-se contra tal Decreto.

A AMB classificou a proposta como um projeto desenfreado do governo de banalização e enfoque mercantilista da formação médica, com objetivo de formar pseudomédicos e pseudoespecialistas em escala industrial e permanecer ludibriando a população, sempre focando na quantidade, e irresponsável e descompromissado quanto à qualidade. Também criticou a falta de diálogo do governo com as EM, que há mais de 50 anos eram responsáveis pela formação de especialistas no País. Para eles, o decreto permitia interferência unilateral do governo nessa formação. As EM afirmaram, inclusive, que todos os especialistas com título válido já estavam registrados no CFM e que o Governo tinha acesso a esses dados. Dessa forma, para eles, o decreto escondia outros interesses, não apenas o de cadastrar os especialistas do País. A medida do governo federal se mostrava 'contra os médicos' (AMB, 2016).

A publicação desse documento mobilizou diversas entidades representativas da categoria médica em torno de propostas de mudança, tendo em vista a abertura de brechas nos critérios de formação de médicos especialistas no Brasil. Como consequência, as entidades se articularam com representações do legislativo, com o então Presidente da Câmara dos Deputados Eduardo Cunha, com a participação de outros deputados da oposição e lideranças de vários partidos no intuito de informá-los e sensibilizá-los dos perigos a respeito do Decreto $\mathrm{n}^{\circ}$ 8.497/2015. De autoria do deputado Mandetta (DEM-MS), o Projeto de Decreto Legislativo (PDL 175/2015) atendia às reivindicações das entidades médicas contrárias à criação do cadastro. Cunha deu ao governo prazo de quinze dias para que o MS e as EM entrassem em 
acordo. Como resultado desse processo houve recuo do governo federal e criação de Comissão composta por parlamentares, Ministérios da Saúde e da Educação e entidades médicas para que entrassem em consenso e construíssem um novo texto, o qual foi publicado no Decreto $\mathrm{n}^{\mathrm{o}}$ $8.516 / 15$.

\section{Movimento médico em 2015 e 2016}

Em janeiro de 2015, ocorreu a retomada do diálogo entre categoria médica e MS, que, segundo as EM, foi interrompido em 2013 por ocasião do lançamento do PMM. Isso se deu por meio da Fenam e dos sindicatos médicos que participaram em Brasília de audiência com o então ministro da saúde, Arthur Chioro.

Esse processo de mobilização por condições de trabalho e salário para os médicos, desdobrou-se na criação da Frente Nacional em Defesa da Saúde, da Medicina e do Médico, lançada em 16 de junho de 2015. Essa Frente tinha como objetivo fortalecer e unir as instituições em defesa do médico e da medicina, e impedir que as EM fossem aparelhadas pelo governo e por partidos políticos. Contraditoriamente, para colocar a 'Frente' em ação, houve articulações das EM com parlamentares e representações de partidos considerados conservadores, opositores do governo em análise.

Cabe destacar o apoio recebido pelas EM de governantes e parlamentares em 2015, particularmente do então Vice-Presidente da República, Michel Temer. Em um encontro entre a Fenam e Temer, foram expostas as bandeiras de lutas defendidas pela Federação e as principais conquistas. Relataram-se, também, as dificuldades nas relações com o governo federal, em especial na questão dos vetos à Lei do Ato Médico e da implantação do PMM. Em outra oportunidade, a Fenam se reuniu com então Presidente da Câmara dos Deputados, Eduardo Cunha, para expor as preocupações da categoria com a saúde, com a democracia e questões relacionadas às liberdades individuais, a reforma política e a crise econômica (FENAM, 2016).
Como resultado do processo de mobilização e articulação entre EM e atores do poder legislativo, as entidades apoiaram a Proposta de Emenda Constitucional - PEC n ${ }^{\circ} 454 / 09$, de autoria do deputado Ronaldo Caiado (DEM/GO), que dispõe sobre a criação da carreira de Estado única para a categoria médica. Essa PEC estabelece diretrizes para a organização de uma carreira única de médicos mantida pela União, mas com exercício no serviço público federal, estadual e municipal; a remuneração respeitará um piso profissional nacional fixado por lei e valorizará o tempo de serviço e os níveis de qualificação na área médica.

Já no ano de 2016, com a crise política instalada no País e o afastamento da então presidente Dilma Rousseff em julgamento pelo impeachment, as EM anunciaram que iniciariam estratégias para se articularem com as pastas do governo interino de Michel Temer para seleção de pleitos para a categoria. A Federação expôs o interesse em marcar audiências com os titulares das pastas que interferem no trabalho do médico, como os ministros do trabalho, saúde e educação, dentre outros. O CFM noticiou que se reuniu com os ministros da saúde, Ricardo Barros, e da educação, Mendonça Filho, para discutir temas de interesse para a medicina, como o ensino e a oferta de assistência em regiões de difícil provimento.

Em julho de 2016, as EM iniciaram um período de mobilizações pela criação da Frente Parlamentar da Medicina (FPMed) com o objetivo de atuar junto ao Congresso Nacional em defesa dos médicos e da rede pública de saúde de todo Brasil. Segundo o CFM,

a Frente será um espaço importante de interlocução dos médicos com o parlamento brasileiro e temos interesse que ela seja fortalecida. (CFM, 2016, N. P.).

Outro mecanismo de defesa dos interesses da categoria médica foi a criação da Confederação Nacional dos Médicos (CNM) 
com o objetivo de ser o topo da representação sindical da categoria, respondendo nacionalmente pelos médicos brasileiros.

\section{Atenção à saúde: a polêmica em tor- no da questão das cesarianas}

Na categoria 'Outros', as novas diretrizes para o parto obtiveram maior expressividade nas notícias veiculadas pelas EM. A publicação da Resolução Normativa $\mathrm{n}^{0} 368$ pela Agência Nacional de Saúde (ANS) e MS com vistas a estimular o parto normal causou desconforto às EM. A resolução previa que as operadoras de planos de saúde, sempre que solicitadas, deveriam divulgar os percentuais de cirurgias cesáreas e de partos normais por estabelecimento de saúde e por médico. Também seriam obrigadas a fornecer o Cartão da Gestante e a Carta de Informação à Gestante, nos quais deveria constar o registro de todo o pré-natal, e exigir que os obstetras utilizem o 'partograma', documento gráfico onde é registrado tudo o que acontece durante o trabalho de parto. No entendimento do Conselho, para se reduzir o número de cesarianas realizadas no Brasil, a solução envolve o aperfeiçoamento dos fluxos de atendimento obstétrico, melhorando a qualificação do serviço de pré-natal e garantindo leitos para todas as gestantes.

A partir daí, intensa mobilização entre as EM começou a ser promovida com o intuito de cobrar ajustes nas normas sobre partos da ANS. Segundo o CFM, a resolução não era clara com relação à autonomia da mulher na realização de cesarianas, assim como o equívoco em condicionar a existência do 'partograma' ao pagamento dos honorários médicos. O único ponto da Resolução considerada como favorável pelo CFM foi o uso do cartão da gestante.

É inadmissível colocar o médico como responsável pelo caos na saúde. Nós somos os verdadeiros heróis e fazemos milagres no atendimento às gestantes. (FENAM, 2016, N. P.).

Em abril de 2016, o MS publicou no Diário Oficial da União o Protocolo Clínico de Diretrizes Terapêuticas (PCDT) para cesariana, trazendo os parâmetros que devem ser seguidos pelas Secretarias de Saúde dos Estados, Distrito Federal e Municípios. A criação do novo documento ocorreu durante meses de discussão e de consulta pública e estabeleceu um modelo de regulação do acesso assistencial, autorização, registro, indicação e ressarcimento dos procedimentos realizados. Diversas entidades, como CFM, AMB e outras sociedades de especialistas, repudiaram o protocolo. Dentre os pontos que geraram grande discordância, estava a dispensa do pediatra na sala de parto nas cesarianas quando não houvesse risco ao feto ou à gestante. Após mobilização das EM, o MS garantiu que faria mudanças no texto.

Em dezembro, numa decisão considerada pelo CFM como 'um divisor de águas', a Justiça Federal determinou que a ANS colocasse em prática novas medidas para reduzir o número de cesáreas na rede particular de saúde. Com a decisão, em prazo máximo de 60 dias, os profissionais de saúde da rede particular que auxiliassem em parto normal deveriam receber dos planos de saúde, no mínimo, três vezes mais do que na realização de uma cesárea.

Em junho de 2016, o CFM publica a Resolução $\mathrm{n}^{0}$ 2.144/2016, que define critérios para cesariana a pedido da paciente no Brasil. Estabelece que, nas situações de risco habitual e para garantir a segurança do feto, somente poderá ser realizada cesariana a partir da $39^{\mathrm{a}}$ semana de gestação. Recomenda, também, que, nas primeiras consultas de pré-natal, o médico e paciente discutam sobre benefícios e riscos tanto do parto normal como da cesariana, bem como sobre o direito de escolha da via de parto pela gestante. Quando decidido pela 
realização de parto cesariano a pedido, passa a ser obrigatória a elaboração de um termo de consentimento livre e esclarecido pelo médico para que seja registrada a decisão da parturiente.

\section{Posicionamento das EM sobre a con- juntura nacional}

No ano de 2015, após a reeleição da presidente Dilma Rousseff, as EM carregaram em críticas e posicionamentos desfavoráveis ao governo. A popularidade da então presidente Dilma Rousseff e do Partido dos Trabalhadores (PT) havia despencado e atingido a pior marca de seu governo. Por diversas ocasiões, as EM declararam apoio às manifestações contrárias ao governo vigente, bem como conclamaram os médicos a aderirem aos movimentos pró-impeachment sob o slogan 'corrupção faz mal à saúde!' Na ocasião, foi mencionado pelas EM o pronunciamento do senador Aécio Neves que "O Brasil despertou. É o povo na rua que vai permitir a superação da crise. Não é este governo, que não tem mais autoridade, nem credibilidade" (FENAM, 2016, N. P.).

Em apoio aas manifestações populares, a Fenam, afirmou:

[...] dia 15 de março de 2015, dois milhões foram às ruas para resgatar o país e retomar a nossa tradição de respeito à liberdade, à democracia, aos valores morais, éticos e religiosos que forjam nossa nacionalidade. E o verde amarelo de nossa história inundou as cidades. Dia 15 de março marca o início de um novo tempo. (FENAM, 2016, N. P.).

Em 2016, a crise política e econômica se agravava no País, ocorre a abertura do processo de impeachment contra a presidente eleita e acirrou-se a efervescência da operação Lava Jato. À época, a Fenam manifestou-se afirmando apoio total e irrestrito ao juiz Sérgio Moro, ao Ministério Público Federal, à Polícia Federal e a toda equipe que faz as investigações dos envolvidos nos desvios de recursos do Estado.

Com o fim do julgamento do processo de impeachment da presidente Dilma Rousseff e o seu afastamento definitivo das funções presidenciais, a Fenam afirmou que estava otimista naquele momento de mudança de perspectiva sobre os novos rumos do País.

[...] A categoria médica sofreu durante os últimos três anos uma perseguição, houve tentativas de culpar o médico pelo caos na saúde, e hoje se inicia um governo que será acompanhado de perto pela entidade. Segundo o presidente da Fenam, Otto Baptista, uma página está sendo virada para toda a classe médica. 'Acabamos de deixar para trás toda aquela perseguição em cima do Ato Médico, do sucateamento da própria saúde pública, o subfinanciamento, a abertura de escolas indiscriminada e até a entrada de intercambistas sem o revalida. Estaremos vigilantes, apoiando a classe médica e acompanhando o que vier de bom e melhor deste governo. Estamos juntos.', concluiu o presidente Otto. (FENAM, 2016, N. P.).

\section{Discussão}

A interferência das políticas governamentais sobre questões que envolvem o trabalho e a educação médica, isto é, a 'geração de empregos', a 'distribuição' territorial da força de trabalho em saúde, a 'política salarial', a 'formação' e outros aspectos relacionados foi a principal causa de rejeição do conjunto das EM. No período estudado, as EM foram ativas nas críticas 'negativas' apresentadas aos programas do governo federal e ao PMM em particular, de modo que o PMM e seus desdobramentos revigoraram a ideologia liberal em torno da prática médica presente nas origens da RSB (CAMPOS, 1988; DONNÂNGELO, 1975).

A polêmica em torno do PMM contém controvérsias na literatura. Enquanto as EM reforçam que o programa é uma farsa, 
um reforço à ditadura cubana, dentre outras questões, os trabalhos produzidos sobre a implantação do PMM revelam melhoria dos indicadores de saúde (ALENCAR ET AL., 2016), assim como da satisfação dos usuários atendidos pelo Programa (melo et Al., 2016). Além disso, segundo Souza (2014), as EM representam um discurso discriminatório, de exaltação aos médicos brasileiros, enquanto desqualificam os médicos cubanos. Esse discurso é atenuado, segundo o mesmo autor, à medida que o Programa se consolida e a população defende a permanência dos médicos estrangeiros, particularmente os cubanos.

Por outro lado, a abertura de novos cursos de medicina e os argumentos das EM sobre a privatização do ensino médico encontram reforço nos resultados do trabalho de Silva Jr. et al. (2014), que comprovam que a abertura de cursos no interior do País não garante a fixação do médico no futuro. Para as EM, o PMM representa uma política de governo com 'claros' interesses políticos e cuja baixa adesão dos profissionais brasileiros no período estudado é fruto das 'péssimas' condições de trabalho na atenção primária no Brasil.

As tensões entre a EM e o governo federal permearam todo o Governo de Dilma Rousseff desde os vetos da então presidente a artigos da Lei do Ato Médico (GUIMARÃEs; REGO, 2005). No período estudado, as EM reclamam por terem sido excluídas dos processos de negociação relacionados ao PMM e seus desdobramentos, quer seja da elaboração das novas diretrizes curriculares; da construção do cadastro nacional de especialistas; ou do debate sobre a distribuição das novas vagas em cursos de medicina. Essas questões geraram intensa oposição das EM ao governo Dilma, cujos embates foram responsáveis pelo apoio e mobilização das EM pelo processo de impeachment da presidente em 2016.

Nesse particular, as EM promoveram articulações com atores do legislativo, a exemplo daquelas com Eduardo Cunha (Partido do Movimento Democrático Brasileiro - PMDB), Michel Temer (PMDB),
Luiz Henrique Mandetta (DEM) e Ronaldo Caiado (DEM) para viabilizar a implantação de projetos a favor dos interesses médicos ou, então, impedir aqueles que causaram descontentamento da categoria e seus interesses corporativos.

Tais articulações foram responsáveis pelo recuo do governo federal em determinados momentos, como no caso do decreto $\mathrm{n}^{\circ}$ 8497/2015, embora as EM se posicionassem contra um suposto processo de 'aparelhamento' de entidades por políticos e seus partidos (FENAM, 2016). A posse do vice-presidente após o afastamento da presidente Dilma provocou mudança de discurso nas EM que vislumbravam maior vinculação e convergência entre o projeto político das forças que tomaram o poder e os interesses defendidos pela categoria.

O posicionamento das EM no período e a defesa das questões que envolveram a diminuição da autonomia do trabalho médico reforçam uma ideologia coorporativa e de oposição ao desenvolvimento de um sistema de saúde democrático, universal, público e pautado pelo direito à saúde e pela justiça social. O debate produzido acerca da suposta irresponsabilidade do governo federal em torno do PMM explicita prejuízos para a população carente e reforça O SUS como um programa para pobres (TEIXEIRA; SOUZA; PAIM, 2014), passando ao largo dos princípios e diretrizes da RSB, embora a RSB não se resuma ao SUS (PAIM ET AL., 2011).

Os resultados desse trabalho, ademais, reforçam a reduzida preocupação das EM com a expansão da oferta de serviços para garantir a universalidade, a integralidade e a equidade do cuidado à saúde da população. Esse processo demanda a inserção de profissionais médicos nas unidades de produção de serviços, principalmente no âmbito da Atenção Primária à Saúde, adotada pelo Estado brasileiro como estratégia de reorganização do sistema, tal como explicitada na Política Nacional de Atenção Básica (BRASIL, 2012). 


\section{Comentários finais}

As evidências produzidas por este estudo mostram que as EM posicionaram-se em quase todo o período estudado contra as políticas de saúde do governo federal, particularmente aquelas que contrariavam os interesses da categoria médica. Nesse sentido, o PMM e seus desdobramentos foram temas por elas mais combatidos. Evidenciam, portanto, a manutenção dos interesses coorporativos de um segmento profissional e pouco compromissado com o sistema público de saúde. Ademais, a oposição das EM aos projetos do governo federal para a área da saúde, bem como as diversas alianças do segmento com parlamentares conservadores, foi gerada para benefício dos interesses da corporação. Os resultados deste trabalho evidenciam que as EM e seus projetos afastam-se dos princípios e diretrizes na RSB, assim como dos princípios de diretrizes do SUS.

\section{Colaboradores}

Catharina Matos: Contribuiu na concepção, planejamento e análise do artigo. Elaborou o rascunho e aprovou a versão final do artigo.

Mayara Freitas: Contribuiu na concepção, planejamento e análise do artigo. Elaborou o rascunho e aprovou a versão final do artigo.

Carmem Fontes Teixeira: Realizou a revisão crítica do artigo e a aprovação final do manuscrito.

Jairnilson Silva Paim: Realizou a revisão crítica do artigo e a aprovação final do manuscrito.

\section{Referências}

ALENCAR, A. P. A. et al. Impacto do Programa Mais

Médicos na atenção básica de um município do sertão central nordestino. Revista Eletrônica Gestão \& Sociedade, Belo Horizonte, v. 10, n. 26, p. 1290-1301, maio/ago. 2016.

ALENCAR, T. S. A Reforma sanitária e a questão medicamento/assistência farmacêutica. Salvador, 2016. 442 f. Tese (Doutorado em Saúde Pública) - Instituto de Saúde Coletiva, Universidade Federal da Bahia, Salvador, 2016.

\section{ASSOCIAÇÃO MÉDICA BRASILEIRA (AMB).}

Disponível em: <https://amb.org.br/category/noticias/>. Acesso em: 10 dez. 2016.
BAHIA, L. A saúde em banho-maria. In: OS ANOS

Lula: contribuições para um balanço crítico 2003-2010.

Rio de Janeiro: Garamond, 2010. p. 351-368.

BRASIL. Ministério da Saúde. Secretaria de Atenção à Saúde. Departamento de Atenção Básica. Política Nacional de Atenção Básica. Brasília, DF: MS, 2012.

CAMPOS, G. S. Os médicos e a política de saúde. São Paulo: Hucitec, 1988.

\section{CONSELHO FEDERAL DE MEDICINA (CFM).}

Disponível em: <http://portal.cfm.org.br/index. php?option=com noticias\&buscaEfetuada $=$ true $\&$ notic iasAno $=\&$ noticiasTexto $=\&$ noticiasExibir $=20>$. Acesso 
em: 10 dez. 2016. Não paginado.

COSTA, A. M. Onde foi parar o sonho do SUS? Le Monde: Diplomatique Brasil, v. 69, p. 30-31, 2013. Disponível em: <http://diplomatique.org.br/onde-foi-parar-o-sonho-do-sus/>. Acesso em: 29 ago. 2017.

DONNANGELO, M. C. F. Medicina e sociedade: o médico e seu mercado de trabalho. São Paulo: Livraria Pioneira, 1975.

ESCOREL, S. Reviravolta na saúde: origem e articulação do movimento sanitário. Rio de Janeiro: Fiocruz, 1998.

FEDERAÇÃO NACIONAL DOS MÉDICOS (FENAM). Disponível em: <http://www.fenam.org.br/site/ noticias_fenam.php> Acesso em: 10 dez. 2016. Não paginado.

GOMES, L. B. A atual configuração política dos médicos brasileiros: uma análise da atuação das entidades médicas nacionais e do movimento médico que operou por fora delas. Rio de Janeiro, $300 \mathrm{f}$. Tese (Doutorado em Medicina) - Centro de Ciências da Saúde, Faculdade de Medicina, Universidade Federal do Rio de Janeiro, 2016.

GUIMARÃES, R. G. M.; REGO, S. O debate sobre a regulamentação do ato médico no Brasil. Ciência \& Saúde Coletiva, Rio de Janeiro, v. 10, n. supl., p. 7-17, 2005.

MACHADO, C. V.; BAPTISTA, T. W. F.; LIMA, L. D. (Org.). Políticas de saúde no Brasil: continuidades e mudanças. Rio de Janeiro: Fiocruz, 2012.

MELO, C. F.; BAIÃO, D. C.; COSTA, M. C. A percepção dos usuários cearenses sobre o Programa Mais Médicos. Revista Eletrônica Gestão \& Sociedade, Belo Horizonte, v. 10, n. 26, p. 1302-1312, maio/ago. 2016.

OCKÉ-REIS, C. O.SUS: o desafio de ser único. Rio de
Janeiro: Fiocruz, 2012.

PAIM, J. S. Reforma sanitária brasileira: contribuição para compreensão e crítica. Salvador: Edufba; Rio de Janeiro: Fiocruz, 2008

PAIM, J. S.; ALMEIDA-FILHO, N. Saúde coletiva: teoria e prática. Rio de Janeiro: Medbook, 2014.

PAIM, J. S. et al. The Brazilian health system: history, advances, and challenges. The Lancet, Londres, v. 377, p. 1778-1797, 2011.

RIBEIRO, R. C. Programa Mais Médicos: um equívoco conceitual. Ciência \& Saúde Coletiva, Rio de Janeiro, v. 20, n. 2, p. 421-424, fev. 2015.

SILVA JUNIOR, A. G. et al. Oferta de vagas de graduação e residência médicas no estado do rio de janeiro a partir do Programa Mais Médicos (2013-2015). Revista Eletrônica Gestão \& Sociedade, Belo Horizonte, v. 10, n. 26, p. 1347-1359, maio/ago. 2016.

SOUZA, L. Representação do Programa Mais Médicos pelo site do pragmatismo político e pelo portal do

Conselho Federal de Medicina. 2014. 144 f. Dissertação (Mestrado em Linguística) - Universidade de Brasília, Brasília, DF, 2014.

TEIXEIRA, C. F.; PAIM, J. S. A política de saúde no governo Lula e a dialética do menos pior. Saúde em Debate, Rio de Janeiro, v. 29, n. 31, p. 268-283, 2005.

TEIXEIRA, C. F.; SOUZA, L. E. P. F.; PAIM, J. S.

Sistema Único de Saúde (SUS): a difícil construção de um sistema universal na sociedade brasileira. In: PAIM, J. S.; ALMEIDA-FILHO, N. (Org.). Saúde Coletiva: teoria e prática. Rio de Janeiro: Medbook, 2014. p. 121-137.

Recebido para publicação em julho de 2017

Versão final em agosto de 2017

Conflito de interesses: inexistente

Suporte financeiro: não houve 